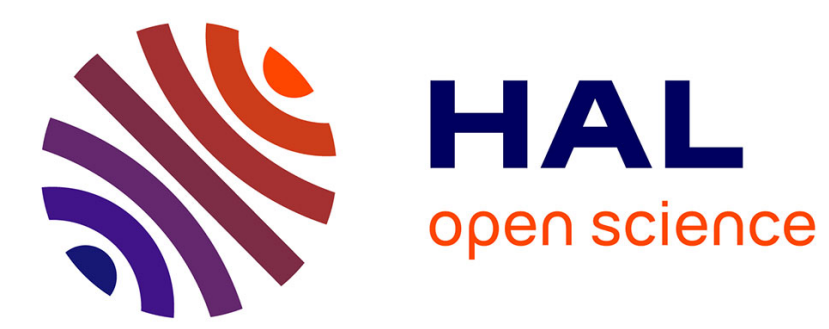

\title{
Inter-organisational projects in french innovation clusters: the construction of collaboration
}

\author{
L. Calamel, C. Defelix, T. Picq, D. Retour
}

\section{To cite this version:}

L. Calamel, C. Defelix, T. Picq, D. Retour. Inter-organisational projects in french innovation clusters: the construction of collaboration. 2010. halshs-00534712

\section{HAL Id: halshs-00534712 \\ https://shs.hal.science/halshs-00534712}

Submitted on 10 Nov 2010

HAL is a multi-disciplinary open access archive for the deposit and dissemination of scientific research documents, whether they are published or not. The documents may come from teaching and research institutions in France or abroad, or from public or private research centers.
L'archive ouverte pluridisciplinaire HAL, est destinée au dépôt et à la diffusion de documents scientifiques de niveau recherche, publiés ou non, émanant des établissements d'enseignement et de recherche français ou étrangers, des laboratoires publics ou privés. 


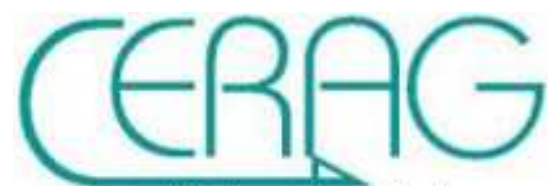

Centre d'E tudes et de Recherches

Appliquées d la Gestion C.N.R.S UMR 5820

CAHIER DE RECHERCHE $n^{\circ}$ 2010-01 E1

INTER-ORGANISATIONAL PROJECTS IN FRENCH

INNOVATION CLUSTERS: THE CONSTRUCTION OF

COLLABORATION

Ludivine Calamel

Christian Defélix

Thierry Picq

Didier Retour 


\section{INTER-ORGANISATIONAL PROJECTS IN FRENCH INNOVATION CLUSTERS:}

\section{THE CONSTRUCTION OF COLLABORATION}

Ludivine Calamel (Université de Grenoble, CERAG UMR 5820)

Christian Defélix (Université de Grenoble, IAE and CERAG UMR 5820)

Thierry Picq (EM Lyon)

Didier Retour (Université de Grenoble, IAE and CERAG UMR 5820)

Address: Thierry Picq, EM LYON Business School, picq@em-lyon.com 


\title{
INTER-ORGANISATIONAL PROJECTS IN FRENCH INNOVATION CLUSTERS: THE CONSTRUCTION OF COLLABORATION
}

\begin{abstract}
Having received considerable attention from central government and local authorities, French innovation clusters (the so-called 'pôles de compétitivité') are beginning to be studied by academic researchers and evaluated by consultants. The core of their activity consists of collaborative projects, which are characterised by specific management and HR practices located at the junction of different cultures and employment statuses. Almost four years after they were launched, what can we say about the dynamic of these collaborative projects? What is the reality of such collaboration when it involves multiple partnerships bringing together employees from different occupational cultures and HRM systems?
\end{abstract}

The aim of this longitudinal research, which is based on observation of two collaborative projects in one of the most largest clusters in France, is to discuss management and HR issues in such a setting. A literature review highlights the need to open up the 'black box' of collaboration within projects and encourages examination of both manager's coordination efforts and the actors' motivation to cooperate, as well as the role played by HRM practices. Thus observation of the conduct of the projects over two years reveals that collaboration, far from being a given within these projects, is the product of a process of social construction that might be fostered by better managerial support.

Key words: innovation cluster, collaborative project, coordination, cooperation, learning, competences. 


\section{Introduction}

'It is easy to find hundreds of project management books. But the collaborative project management manual is still to be written ... '. . By definition, the collaborative projects referred to here bring together workers from different organisations and employers. They have long been standard practice in international research projects, particularly European ones, and are also the standard mode of operation in innovation clusters.

These clusters (Porter, 1998) à la française, with their government certification, are defined as 'a combination, in a given geographic space, of companies, training centres and public and private research institutes working in partnership in order to create synergies around joint projects of an innovative nature' (DATAR, 2004). The first 66 clusters were certified by the government in 2005 on the basis of a call for tenders. Since then, they have been charged with the task of encouraging and supporting $R \& D$ and innovation projects likely to produce national competitive advantages.

The innovation clusters have received considerable attention from central government and local authorities and are now beginning to be studied by academic researchers (Retour coord., 2009) and evaluated by consultants. However, there is as yet little information available on what happens within the clusters and the projects conducted there, although several observers have wondered about the reality of collaboration between workers with different employment relationships: 'Human resource management within an innovation cluster is not simple: the various populations working there have very different employment statuses and occupational cultures (researchers, entrepreneurs, employees) and most of the individuals associated with the cluster are neither managed nor paid by the cluster' (CM international et al., 2008, p. 105). 
Within an innovation cluster, it is precisely within collaborative projects that these management and HR practices come into contact with each other, at the meeting point of different employment statuses and occupational cultures. Curiously, however, collaboration between partners working on the same project is seldom presented as problematic: the primary objective of those responsible for the governance of the clusters is to endow the projects with the necessary legal and financial resources, as if the ability of those involved to work together effectively can be taken for granted. Over the four or five years of a collaborative project, what is the reality of collaboration between engineers and researchers from different organisational backgrounds likely to be? What obstacles will be encountered and how might they be overcome?

Far from being a given, collaboration in innovation clusters and the projects conducted there has to be constructed and encouraged. A literature review will help us better understand these clusters as organisations based on collaborative projects. The subsequent description of two projects being observed will provide factual evidence, which will serve as a basis for analysing and discussing the gradual process of constructing that collaboration.

\section{Project work in innovation clusters: the issue of collaboration}

\section{Innovation clusters: an emerging organisational form}

Innovation clusters have only recently emerged as an organisational form on to the European and, particularly, French scene and to date have received relatively little attention. Innovation clusters, and indeed clusters more broadly, can be approached from a general organisational networks perspective. Such networks involve the interaction of at least two legally separate firms (Heitz, 2000). Networks differ from both markets and hierarchies (Powell, 1990), bringing together companies with independent capital bases 'within the same value-added

\footnotetext{
${ }^{1}$ Quote from Yves Jongen, head of Mecatech, Belgium innovation cluster, 03/03/2009, Liege.
} 
chain' (Fréry, 1996). Among all the possible types, Ebers and Jarillo (1997) call attention to industrial networks, which bring together different organisation, including firms, trade unions and state agencies, that have recurrent links and supply a particular market. They may take the form of industrial districts, local productive systems or American-style clusters.

France has chosen to give the name 'pôles de compétitivité' to network initiatives established by the public authorities (in contrast to industrial districts, which tend to emerge spontaneously) and involving a variety of partners (unlike local productive systems, which are based solely on firms). DATAR, the French regional development agency, defined them thus (2004): 'a combination, in a given geographic space, of firms, training centres and public and private research institutes working in partnership in order to create synergies around joint projects of an innovative nature'. Sixty-six clusters were designated by the government in 2005 on the basis of a call for tenders; they have since been charged with the task of encouraging and supporting $\mathrm{R} \& \mathrm{D}$ and innovation projects likely to produce national competitive advantages.

The importance the French state accords to innovation clusters can be measured by the size of the budgets allocated to them: one and a half billion Euros for the first phase (2006-2008), and the same amount for the following three years (2009-2011).

In 2008 , a national evaluation of the 71 French clusters found that 39 of them had met their targets and a further 19 had done so only partially, while 13 others were to be extensively reconfigured. The contrasting results of this first official evaluation show that, as yet, we know very little about the actual functioning of the clusters and of the conditions that might lead to success.

Existing studies deal mostly with the clusters as organisational structures and the conditions under which they emerged (Schaer, 2006; KPMG, 2007) or with their territorial embeddedness (Fen-Chong, 2006; Daudé, 2007; Dherment-Ferère and Bidan, 2007), or they discuss their real innovation potential (Darmon, 2006; Duranton et al., 2008; Arzeni et al., 
2008). There is not yet any research targeting what happens inside these clusters, although several observers have raised questions about the reality of the collaboration between workers whose employment relationships differ considerably: 'The management of human resources in an innovation cluster is no simple matter: the various groups working there have very different employment statuses and cultures (researchers, entrepreneurs, salaried staff) and most of the individuals associated with the cluster are neither managed nor paid by the cluster itself' (CM international et al., 2008, p. 105).

Another potentially fruitful approach to innovation clusters offers itself to those seeking to tackle this question. In this approach, clusters are seen as project-based organisations (PBOs) constituted on the basis of inter-organisational collaborative R\& D projects (Hobday, 2000).

\section{Collaborative projects in PBOs: the human factor}

Broadly defined, the term PBO includes all organisations that carry out their core operations in project form. In PBOs, projects are the dominant form of activity and value creation and source of revenue (Hobday, 2000). However, this general statement conceals a more complex and multiform reality, and the recent literature identifies various different types of PBOs (Hobday, 2000). Among them, the project-based enterprise (or what Söderlund calls the 'pure temporary organisation'), defined as a temporary venture designed and implemented for a one-off, non-repeated operation, is the model best suited to the temporary R\&D consortiums found in innovation clusters. In these "single-project organisations" (De Filippi \& Arthur, 1998), the entire organisation is dissolved after completion of the project and totally disappears. The literature on this project-based enterprise model highlights specific issues, such as trust building and managing cultural differences among different individuals (Drouin and al, 2009), coordination of members or inter-organisational cooperation between different partners and the question of survival in a context in which the project-based enterprise is disbanded once the project is over (De Filippi \& Arthur, 1998). 
There are as yet few studies of the need to support this objective of collaborative activity on the human level. Thus a briefing note by the Conseil d'Analyse Stratégique (Council for Strategic Analysis), following a study of 10 French clusters carried out by the Alpha and Geste consultancies (2008), concludes that, to date, the issues of employment, training and competences seem to have been only minor concerns for the actors in the clusters, who are said to have 'difficulty in stepping outside of a framework consisting of narrowly defined scientific and technical knowledge in order to adopt a more general approach to needs: managerial competences, project management, etc.' (Bertrand, Eksl and Dayan 2008, p. 7). For their part, drawing on experience with the clusters in the Région Rhône-Alpes region, Colle et al. (2009) note that the preoccupation with questions around human resources, however recent it may be, is likely to increase, and suggest that particular attention should be paid to collaborative projects.

Specialised research has recently emerged, dealing with specific HR and management issues and practices in the context of inter-organisational projects. This literature, based on empirical research, identifies three areas in the management of collaborative projects requiring particular attention.

- The first is the constitution of the team. Barnes et al. (2006) emphasise the need to take account of cultural compatibility when selecting partners. Winter et al. (2007) highlight the importance of the social process between the actors which, in their view, is the key factor in determining the success of such projects and must, therefore, be facilitated. Kadefors et al. (2007), drawing on their observation of ten collaborative projects in the construction industry, also conclude that the selection of good technical competences, with the appropriate resources, is a key phase in collaborative projects.

- The second is coexistence and the quality of joint work. As early as the year 2000, Boddy and Macbeth, drawing on a questionnaire-based survey of 100 firms involved in collaborative projects, had identified agreement among the parties on the project 
objectives as the most important factor in determining success. Hinkin et al. (2007) also have this agreement on objectives in their list of critical ingredients that have to be present, and they add to it mutual respect, time and trust. This collaborative attitude does not necessarily come naturally. Ratcheva (2009) warn about the different barriers that are at work and the different, even contradictory values for which, in certain cases, they are the vehicles. Going beyond values alone, Shore and Cross (2005) observe that the HR dimension may be an obstacle to collaboration when differences in pay and rewards are too great.

- The third and final point concerns attitudes to learning. In a 1995 article, Browning et al. were already giving an account of a change in the fortunes in the Sematech consortium in the semi-conductor industry: despite the initial ambiguities and confusion (caused by illdefined objectives and cultural differences), a 'moral community' had emerged on the basis of unconditional commitment, visible reciprocity and efforts to improve communications. Mothe and Quelin (2007), drawing on the Eureka R\&D consortia, have confirmed the importance of this kind of attitude among the various parties, as well as of the motivation to collaborate and a commitment to the learning process.

\section{Collaboration within projects: a 'black box' to be opened}

Collaborative projects within the clusters can be seen as a paradoxical form of organisation: on one hand, they are the obvious and natural form of work organisation best suited to interorganisational partnerships, on the other hand, the actors involved face many specific issues that traditional managerial practices and HR systems cannot fully address. The state-of-the-art review suggests they could be seen as a 'black box' that needs to be opened wide.

Since the available literature suggests that human collaboration on such projects does not come naturally but has to be developed, we constructed an analytical framework, based on 3 
factors, to open this 'black box' of collaboration and better understand how performance is built in such a context.

- The first factor comprises intentional or deliberate actions, which we group together under the term 'coordination'. This has not only been a standard variable in organisational analysis since Mintzberg (1989) but is also a focus of attention in the literature on collaborative projects with regard to the constitution of teams. How do project managers structure and put together the partners' various contributions? What modes of coordination do they provide themselves with? (Gerwin and Ferris, 2004)

- The second factor is the stance or attitude of members themselves towards the project, their willingness (or reluctance) to work together which, following on from the study by Picq and Retour (2001), we will term 'cooperation'. Coordination, after all, is hierarchical, mandatory and based on procedures, whereas cooperation is based on mutual adjustment (Mintzberg, 1989) and is voluntary. Thus do the human resources involved in the project show a desire to work together, despite differences in methods and cultures? (Dameron \& Joffre, 2007)

- The third and final factor is the HRM contribution. Existing literature points out that HR practices may be seen as either an obstacle or a lever in building project collaboration. They may be a risk if there is too great a gap between the incentive and remuneration systems of the various employers, but an opportunity if practices that facilitate team formation or group esteem can be developed. What support measures might be put in place in order to build up the team, manage contributions and remuneration and develop competences? Is there is a perceived or real role for HRM in this regard? (Bredin, 2008) 
Figure 1 : A model to open the 'black box' of collaborative R\&D projects

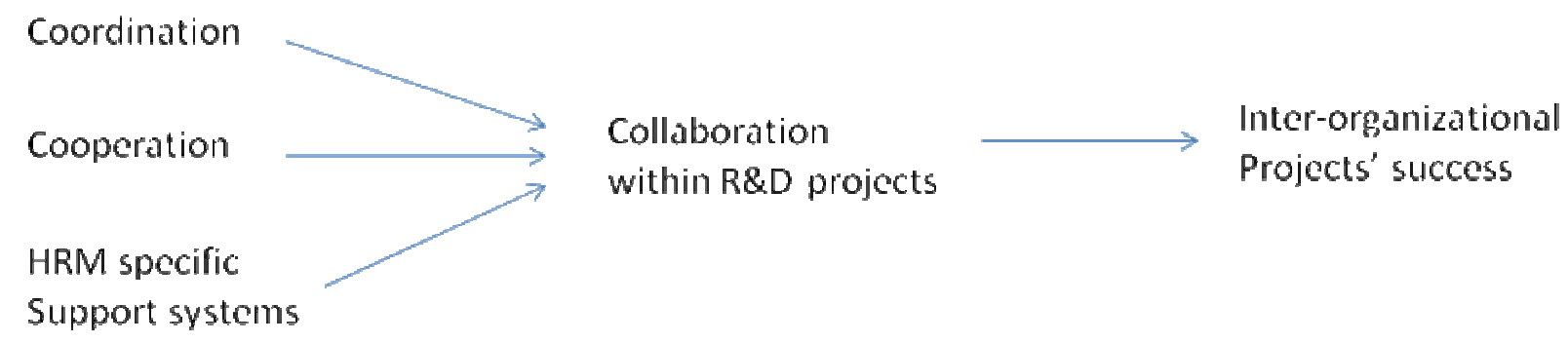

In order to better understand the reality of collaboration within projects and what can be done to develop it, we will apply this framework to two different case studies of collaborative R\&D projects in a French innovation cluster.

\section{Case study: two projects in search of collaboration}

Our field research took place in a so-called 'global innovation cluster', which is a state certified cluster subject to considerable pressure from the public authorities to play a leading role in winning the innovation battle and to which various funding bodies have committed large sums of money. The cluster in question was Minalogic, one of the six French global clusters. Minalogic stands for 'MIcro NAnotechnologies et LOgiciel Grenoble-Isère Compétitivité': its goal is to establish a centre for intelligent miniaturised products and solutions for industry by pooling resources in micro and nanotechnologies and software technologies. Today, more than 140 actors have decided formally to join forces in the new innovation cluster: they include companies (in the fields of microelectronics and software), training and research organisations, local authority agencies and of course microelectronic and software companies, both SMEs (more than 80) and 'heavyweights' of technological innovation such as the Commissariat à l'Energie Atomique (the French atomic energy 
commission) and major companies such as Schneider Electric and STMicroelectronics. Since 2006, MINALOGIC has launched 150 approved projects, involving a total expenditure of 1.2 billion Euros, on which employees from different organisations are supposed to work together.

\section{A methodology based on longitudinal observation}

The classical strand of the project management literature is primarily based on relatively broad surveys designed to identify the factors that determine a project's success. Following

Söderlund's (2005) recommendations, we argue that process-oriented qualitative methodologies may prove more effective than survey research in revealing the deep structures and the dynamic nature of complex human systems such as inter-organisational project collaboration. To support this argument, we conducted a longitudinal investigation of 2 collaborative R\&D projects taking place within MINALOGIC. With the assistance of R\&D managers and HR people from the firms involved in this cluster, we were able to investigate two collaborative projects launched soon after Minalogic was set up but with fairly different profiles, which we here designate project A and project B.

Within the Minalogic cluster, project A comes under the embedded software family; its objective is to develop technological components that will contribute to improved energy efficiency. Against the background of European energy reduction targets, the aim is to manage electrical energy intelligently and to gain a better understanding of the distribution and use of electricity. The particular purpose of project A is to develop an intelligent electric switchboard capable of communicating and interfacing with its environment and evolving rapidly through the use of miniaturised electronics and highly integrated software. A large, market-leading company in the field of electrical equipment (which we will call GEL) has brought together 11 partners to work on the project: five other large companies in the IT, telecommunications and electricity supply industries, together with three SMEs and three 
research institutes. With a budget of 20.5 million euros over four years, project A will take up 127 person-years and started in January 2007.

The second project investigated, which we call project $\mathrm{B}$, belongs to the other sub-family of projects in the Minalogic cluster, namely semi-conductors. The objective here is to develop new substrates for the integrated circuits used in electronic systems. Based on work in clean rooms, with the constraints on plant and equipment that implies, project B formally involves just three partners: a former start-up in the micro-electronics industry that has become a major player in the industry, an SME that happens to be its subsidiary and a major public research centre. With a budget of 207 million Euros over four years, project B will employ some 100 people - 'many of them full-time' - two thirds of them from the large company and one third from the research centre.

These two projects started officially in 2007 and were planned to last several years (at least four). This context is conducive to longitudinal observation of collaborative practices and their evolution over time. Working with representatives of the companies involved, we devised a protocol that enables us to gather data at regular intervals with the aim of producing snapshots of collaborative practices at different stages in the evolution of the projects (launch, development, maturity, completion). In order to study the early months of these two projects' operation, we conducted 19 semi-structured interviews between October and December 2007: 13 on project $A$ and 6 on project $B$. These interviews focused on the initial launch of the projects, their evolution and on modes of management throughout the first year of their existence. They were conducted with a diverse sample of collaborators involved in the projects. The interviewees represented a variety of partners and had different levels of responsibilities, ranging from project manager, via sub-project manager to mere participant, in order to vary the points of view.

This first series of observations gave rise to three types of feedback, with the research results being presented first to the project managers, then to the managers of the Minalogic cluster 
and finally to all the actors interviewed at a joint feedback session that was combined with an exchange of practices between the two project teams. This last feedback session, held in May 2008, gave the actors present an opportunity to put into words their experiences with collaborative working and to share them with their colleagues. The HR managers of the firms concerned were also informed of the diagnosis; this gave them an opportunity to consider the support measures that needed to be incorporated into these collaborative projects in order to improve their subsequent development.

We contacted these actors again at the end of 2008. Now they had been working on the projects for two years and following the first review of experiences and the support measures put in place, were the actors involved and/or the partner organisations managing to work together better? We got back in touch with each individual we had interviewd previously and used an interview schedule structured around three major themes: the future of the cooperation, coordination measures and tools and the relevance or otherwise of HRM actions. Seventeen of the 19 people interviewed in the first round were interviewed again in this second round: 12 on project A ( 1 manager, 5 of the 6 sub-project managers, 6 team members) and 5 on project $\mathrm{B}$ (1 manager, 3 sub-project managers and 1 team member). It should be noted that 3 sub-project managers on project B had changed jobs or employer in the meantime and could not be contacted again. Figure 2 below gives an overview of this research protocol. 
Figure 2 : Overview of the longitudinal research protocol

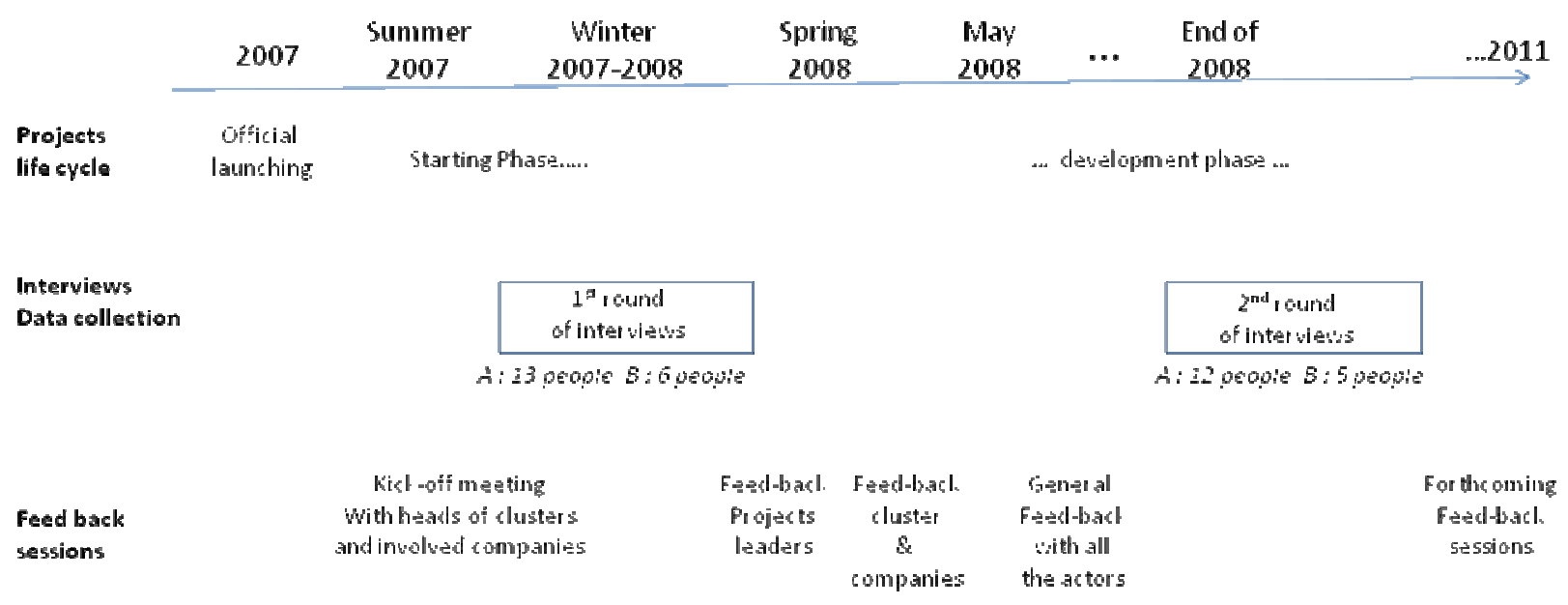

We followed grounded theory recommendations by continually comparing what was emerging from the field and what already existed in the literature (Glaser and Strauss, 1967).

We also included in our data collection protocol information exchanged during the feedback sessions or 'learning' debates with the actors themselves, which was incorporated into the knowledge creation strategy. We decided to adopt a phenomenological approach and take down verbatim what the participants said about their experience. The transcriptions were analysed without any a priori structure, using a qualitative processing method suited to he exploratory nature of our approach. We opted for an inductive, open coding approach (Strauss and Corbin, 1990) in order to reveal phenomena linked to collaborative working on this type of project. This methodology is well suited to the constraints associated with the context, which include, on the one hand, a relatively low level of availability on the part of the actors and, in some cases, significant staff turnover on long-term projects and, on the other, a highly technological and confidential subject matter that makes participant observation impossible. 


\section{Results:}

\section{2 years of Project A: the challenge of managing a fragmented work group}

While the R\&D orientation and the ultimate goal of project $\mathrm{A}$ - the intelligent electrical switchboard - are well established, the objectives were not immediately clear to all those involved in the project, even though GEL seems on initial analysis to be similar to the socalled 'flagship company' in industrial networks (Le Boulaire and Leclair, 2003). 'All that was extremely vague at the outset,' admitted one of the team members, 'each partner had specified the resources they were able to bring to the project, but at the beginning nobody had given any thought to what we were working on'. The project manager, for his part, confirmed that 'the project has evolved over time' and that the search for finance had determined the very nature of the objectives: 'We're involved in foresight projects and not the development of commercial products, which cannot be subsidised'. This early difficulty in effecting the transition from a vision to operational objectives was quickly compounded by another, caused by each partner having specific objectives, some of them explicit, others not: 'each partner has different objectives. (...) Clearly, not all the work being done is directed solely towards the end goal of the project. We're also developing components for ourselves, in related areas'. Managers at an IT services company that is a partner in project A even pointed to a possible conflict: 'There are in fact two strategies, with GEL, the leader, pulling the project towards its own global strategy and the other partners each pursuing their own agendas'.

The management of project A was shaped by the project manager, an experienced engineer from GEL who has managed other collaborative projects. Having played a very active role in putting the financing together, one of his first actions was to divide the project into five subprojects, 'all of them independent of the others, but each one contributing to the overall 
objective'. The sub-projects are also managed by GEL engineers and are being implemented by teams of variable size drawn from the various organisations collaborating on project $\mathrm{A}$. Each sub-project is divided into a number of 'work packages', which are subsets of the overall development process; the sub-project manager is responsible for their execution and delivery and for monitoring progress. The work is supported by a virtual collaborative workspace that enables documents to be shared, but 'the project actors each work in their own firms. Coordination takes place through regular meetings (at least every three weeks), or whenever the need to meet is felt. There are also meetings for each sub-project. I coordinate the whole thing in order to ensure overall coherence' (overall manager of project A). The partners have different views on the project structure and coordination. Many appreciate the effort put into orchestrating the project - 'It's well managed by GEL, at the overall level, reporting etc.' - but some mentioned that there is not always a consensus on the overall project management: 'There is a certain amount of friction'.

In fact, a review of the project's first year, compiled on the basis of the interviews, highlights three important aspects of the reality of working on the project. The first is what project members themselves call 'the culture shock': 'We've had to spend a lot of time sharing competences and definitions'. One industrial engineer highlighted a difficulty he perceived with the academic research centres: 'Academic researchers think it's not worthy if it can be commercialised'. The second aspect is collaborative work itself, which for some is a new and difficult experience; according to one sub-project manager, 'I haven't been given an explanation of how to work with the partners, or whether there's a methodology for being more efficient'. The third aspect is that incentivising practices are still specific to each employer and differ considerably, without either the overall manager or the sub-project managers being able to influence them at all: 'Each partner does their own recruiting'; 'I'm not consulted by the partners' superiors'. 
After two years of working on the project, our interviewees unanimously drew attention to the progress that had been made in everyone's attitude towards working together and their desire to do so. 'All that time we spent in meetings seemed a bit much, but it was time well spent getting to understand each other and equipping ourselves with a common language' (researcher, partner university); 'We took 6 months to get up to cruising speed. (...) Now we're on the same wavelength' (sub-project manager, GEL). Geographical proximity was often cited as the factor that has facilitated this cooperation: 'Proximity is a great help in carrying out the project: if we can't make ourselves understood either on the phone or by email, then we can meet face to face' (sub-project manager).

Thus while cooperation seemed to be burgeoning, we also noted that coordination tools and arrangements, in the sense of support 'from on high' for collaborative work, had been put in place since the previous period of observation. Monthly sub-project meetings, combined with meetings at the more specific level of the 'work packages', had become the norm, assisted by a virtual document sharing space developed by the innovation cluster. What is most striking, however, is the emergence of common media for project participants to report to each other on their progress: 'Reporting was not explicitly carried out, but an implicit consensus has now been reached: as far as production of the deliverables was concerned, for example, everybody had their own view of what constitutes a deliverable. Now we have a common 'Word' template: I think it came from [GEL], but we've appropriated it gradually' (researcher, partner university).

Cooperation might have increased and coordination been strengthened, but had views and objectives fully converged after two years of collaborative working? At first sight, progress had been made towards establishing a common vision of the project, particularly with regard to the start-up phase or the first few months. Thus '[GEL] has understood that the issues at stake were not the same for all of us and that we do not all have the same resources available to us. Due in part at least to [GEL], we have a shared vision'. The management style adopted 
by the sub-project managers, who are in direct contact with the partners, seems to have been the decisive factor in the development of this common vision: 'The difficulty of these collaborative projects (...) is working together as equals and getting the partners to take collegial decisions. In that respect, [the sub-project manager] has been very successful' (engineer, private-sector partner). The quicker than expected completion of a phase of experimentation visibly contributed to the development of a shared vision of the project: 'Completing the beta test was important for a number of reasons. The client was very happy that we were developing something a little innovative with him, and from a purely technical point of view, it clarified things for us a great deal' (sub-project manager).

However, the verbatim statements we collected all suggest that this process of constructing a shared vision is still a work in progress. The first reason for this is that, even though there is a common objective, each partner still has his own, possible secret objectives: 'There are different objectives and not too many common objectives; the common objective as defined by the funders is not really a common objective (manager at the partner SME); 'I; ve always felt that everybody had a hidden agenda! (...) That's part of life on the project, you just live with it' (researcher, partner university). This finding is all the more important since the numerous partners differ considerably in size and status. Thus each one legitimately takes advantage of the collaborative project in order to advance his own interests and objectives. GEL is intending to develp a product incorporating new technologies that it has not yet mastered, the private technological partners are seeking to accelerate the development of technological components that they will be able to reuse and the public research institutes regard the project as an opportunity to test their conceptual advances.

\section{2 years of project $B$ : remaining issues of a collaborative partnership}

Project B is a very different kind of project from the previous one. What strikes one first of all is that there are many fewer partners involved - just three compared with 12 in project A - and 
that they are much closer in terms of sector of activity. Even though the organisations contributing to project B are a large firm, an SME and a research centre, the SME turns out to be a subsidiary of the large firm, which itself was a spin-off from the research centre.

Thus in contrast to the partners in project A, many of whom did not previously know each other, the three partners in project $\mathrm{B}$ had a shared history prior to the emergence of the innovation cluster and were already working together on the development of innovative semiconductor substrates. Indeed, the large firm involved in project B 'has always worked on them, but with [the establishment of the innovation cluster] we now have a framework and funding to continue. (...) Now we have to justify the partnership, which is why we've set new objectives with more resources' (project B manager). Whereas the partners in project A sat down around a table, as it were, in order to bring forth a common project based on GEL's vision, the three partners in project B were already engaged in collaborative work, which the innovation cluster helped to encourage and develop. The encouragement provided by the cluster has been accompanied by a change in reporting activities: [at present], said the project manager, 'We're working with greater rigour. We have to follow rules on reporting, for example; that makes us more forthright, more above board. We have less freedom, since we have commitments to the AII ${ }^{2}$. (...) We submit a monthly report to the AII in the format they stipulate'.

Like project A, project $\mathrm{B}$ is divided into sub-projects (six in this case), each of which is further divided into a number of work packages. However, while the members of project A work in their own respective organisations and coordinate with each other at a distance or through ad hoc meetings, those on project B work together physically, mainly because of the equipment, machinery and clean rooms that are required. For all that, many meetings and considerable adjustment on both sides seem to be necessary: 'There are at least two meetings

\footnotetext{
${ }^{2}$ Agence pour l'Innovation Industrielle/French Industrial Innovation Agency.
} 
a week: one for monitoring progress on the project, the other for planning and practical organisation. There may be more, depending on specific needs. They might be about the quality process, developments on the $R \& D$ side, AII monitoring meetings, preparations for the transfer of activities, etc. '.

This intense communication effort and schedule of meetings is an attempt to deal with a difficulty of working with partners that is both experienced and articulated. Although the project participants have known each other and been collaborating on research programmes for a long time, they still see themselves as being very different. According to the project manager, the research centre 'has a culture of customer satisfaction, but it's based on the commitment of resources, the aim being to seek to understand. [The large partner firm] has a much greater commitment to producing results. I think their understanding of the competitive environment is similar, but they have different notions of time and results. (...) We have to learn to take account of what others find important'. This intercultural difficulty is coupled with another, more institutional difficulty regarding modes of remuneration: 'There is a little problem when [the company] awards its employees project bonuses. They exist in the [research centre] but they're very rare: one or two every ten years!'.

After two years' work on the project, considerable progress had apparently been made in improving the quality of the collaborative work. In project $\mathrm{B}$, the quality of the cooperation was clearly linked to the understanding each partner now had of the issues at stake for the other: 'The [public research institute] is beginning to understand that it's cultural, because its overriding priority is research. However, things are changing and evolving on both sides as we are gradually acquiring a better understanding of each other' (manager of project B, private company); 'In general terms, one is aware of a real desire for partnership; [the private company] recognises the value of [the research institute]. Relations are better, you don't hear any more cutting remarks about schedules...' (engineer, public research institute). 
In terms of tools, it was the body funding project B that imposed a format for recording results and advances, which contributed to the development of formalised coordination: ' $A$ very detailed PowerPoint listing the actions to be taken with a very precise description of the project: achievement of milestones, reviews, evaluation by a third party appointed by OSEO 3 (manager of project B, private company). Consequently, as one interviewee at the partner research institute said, 'we know how we function. We spend less time on the reports; each report can be read on two levels, that's clear to everyone. (...) We've found a way of working together'. In contrast to project A, it was less the experimentation than the fact of working side by side that was facilitating: 'The teams work in physical proximity to each other; there is a series of meetings on the [private company's] side, more for the industrial side, and on the [public research institute's] side for the exploration and research phase' (manager of project B).

Did the fact that the project involves only a small number of partners operating in the same sector facilitate the development of a common vision? We were surprised to note that this was not the case. A year previously, during our first series of observations, we had briefly glimpsed the influence exerted by organisational culture on the priorities set by each of the two partners. Even though the engineers and researchers in the two entities shared a common scientific background (the former having done their PhDs under the latters' supervision), there was a strong 'research' sensibility on one side and a strong 'commercial' sensibility on the other. A year later, the cultural differences remained and threatened to compromise any possible shared vision: 'It's true that the common vision could be improved. We haven't done enough with the [sub-] project managers in this regard. It would be good to strengthen this vision (...). We haven't explained or communicated enough about the end product' (manager of project B). One interviewee on this project from the public research institute agreed, saying: 'Evaluation of the product's final applications could have been an opportunity to

\footnotetext{
${ }^{3}$ A body providing assistance and financial support to French SMEs.
} 

to collaboration'.

\section{Discussion: the collaboration building process within inter-organisational projects}

The findings from the two successive series of observations provide a basis for examining the respective weights of the three determining factors in collaborative work that we put forward in our interpretative framework. Comparing the two projects, it seems to us that the coordination efforts have been necessary but not sufficient. Far from being a given, cooperation is in fact the product of a gradual learning process, in which HRM may be an additional lever that can be mobilised.

\section{Coordination efforts: necessary but not sufficient}

As we have seen, comparison of projects A and B reveals striking differences in scope and organising principle. In project A, the partners are many and various, and not all of them are in the habit of working together. In project B, on the other hand, there are only three partners; they are all from the same sector of activity and have been carrying out joint research work for several years. Thus the innovation clusters provide a framework for collaborative projects which, like these two examples, vary in their degree of 'fragmentation' or 'integration'. However, they both need to build coordination to be able to produce collaboration in a project-based working.

In both projects $\mathrm{A}$ and $\mathrm{B}$, coordination, in the sense of intentional or deliberate actions taken by the project managers, is relatively limited. In fact, most of these managers' work in the start-up phase involved securing the funding and putting in place a plan of action: true, 'we got ourselves in marching order with a specifications sheet', but 'the consortium agreements 
were not signed before the project started, and have still not been signed even now' and 'there's not enough time for project management and that is reflected in the transfer of information and the follow-up on certain actions' (statements by sub-project managers on project A). These views find an echo on project B, where most of the coordination has come not from the project managers themselves but rather from the financers: 'an expert comes to audit by examining any possible deviations from the targets' (sub-project manager on project B).

Coordination on the two projects had already been strengthened by the end of the first year's work. Based initially on guidelines largely imposed by the financers, the coordination has gradually been developed by the project managers themselves. Their efforts have also in part been a response to requests from their collaborators. One sub-project manager on project A insisted that 'that reports be produced and that we document and explain what we're doing', while another suggested 'setting up a collective dashboard'. In the case of project B, it was observed that 'we could do better in terms of organisation by distancing ourselves a little and agreeing on the tools'. As the projects have advanced, so the sub-project managers have also themselves gradually invented the modes of coordination required to compensate for this initial shortcoming. On project A, they now designate leaders for each work package and ask them to follow very specific monitoring and follow-up procedures. Minutes of all meetings have to be made available on line and the existing meetings have been supplemented by 'oneto-one meetings with each sub-project member'. On project $\mathrm{B}$, it became clear after a few months that the internal reporting tools were too diverse - 'there were as many reports as individuals' - and efforts have been made to harmonise them. There has been a progression, as it were, from mutual adjustment alone to the introduction of additional coordination measures such as direct supervision and the standardisation of procedures.

After two years' work on the projects, the coordination arrangements seem to be mature and well established. The partners involved in project A have gradually and tacitly aligned their 
practices with the reporting formats and spreadsheets used by the large company, particularly since their experience of project reviews with the financers persuaded them of the value of so doing. In the case of project $\mathrm{B}$, the form of coordination put in place by the financer developed more rapidly and more explicitly. Figure 3 shows an overview of the coordination building process over time

Figure 3 : The coordination building process over 2 years

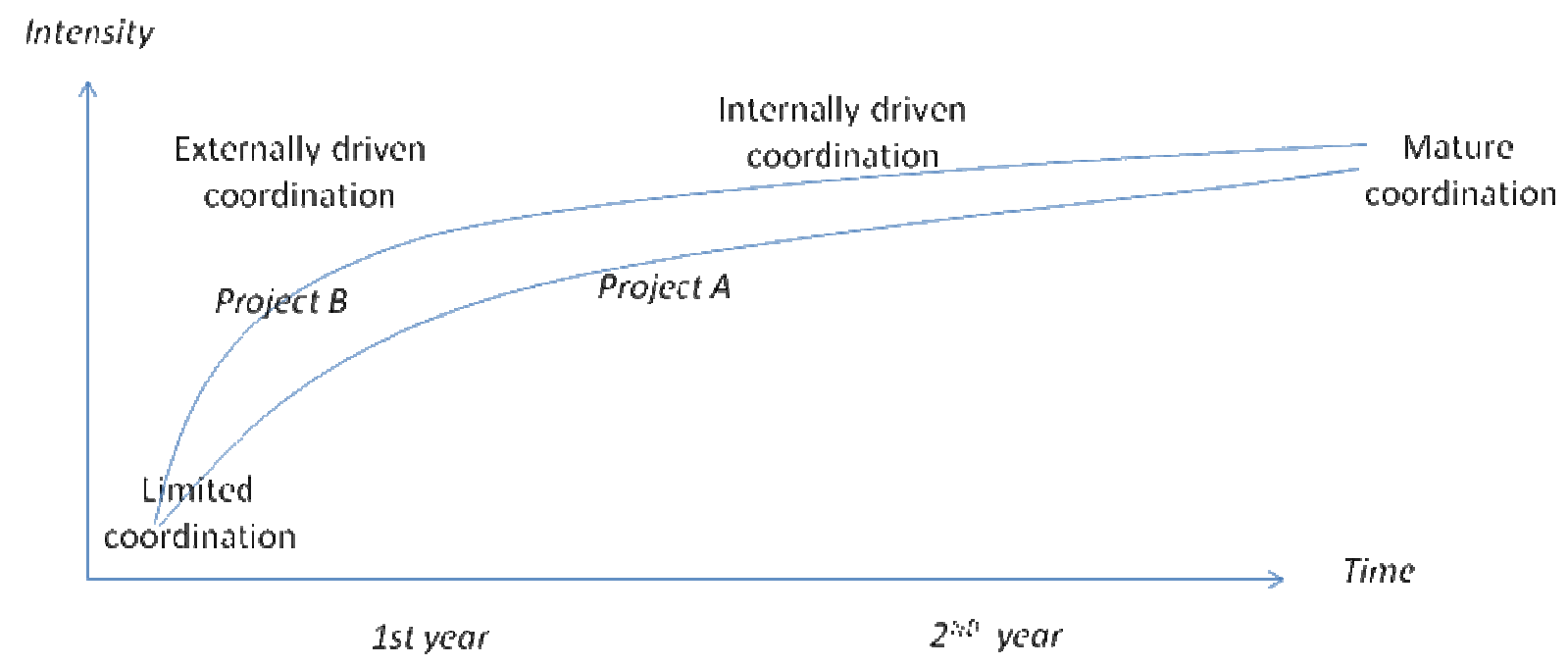

\section{The actors' motivation to cooperate: not intrinsic but acquired}

At the beginning, for both projects, working collaboratively generated spontaneous and relatively strong cooperation on both projects. Besides the intrinsic motivation the participants found in taking up the technological challenges, the value of working with outside organisations was often emphasised: 'This association really did bring us new resources. (...) This makes visible partners whom we wouldn't have seen left to our own devices' (manager at a partner of GEL); 'Projects create links that endure, that are lasting' (university researcher); 'What emerges from the client-supplier relationship is a long-term relationship. One learns more from these projects, the work is not of the same kind' (partner IT service services company). Participants on project B emphasised the fact that, during this start-up phase, 
'there's no major difficulty, the programme is functioning very satisfactorily' and that the partners were very complementary. With cooperation of this kind, what could HRM possibly contribute? There was absolutely no mention of HRM when our interviewees spoke of the project launches. As the manager of project A made clear, 'There's nothing on HRM in the agreements [between the partners]', and thus it is mutual adaptation (Mintzberg, 1989) that prevails and seems to be entirely sufficient for these partners from the same technological culture.

The experience of a year's work on the projects had already revealed some warning signs concerning the initial cooperation. Even on project B, where the partners, few in number, already knew each other and therefore shared a 'common system of reference' (Ruuska and Teigland, 2009), cultural differences became increasingly evident and were not necessarily experienced in a pleasant or amicable way. These differences centred in the first instance on minor points, such as other people's work schedules: 'We're irritated by the remarks [of others] about work schedules at the [public research institute]: they're not justified, it really gets to us' (public researcher). Subsequently, the differences in 'worlds' within multicultural teams (Ratcheva, 2009) emerged into the bright light of day: the public research centre was perceived as wishing 'to go further in seeking understanding, to go right to the heart of things in order to understand them better, and sometimes they have to be restrained because we don't always need to understand things better!' (large company employee). The diversity of cultures, having originally been refreshing, was also perceived as a real challenge to be taken up on a daily basis in project A. Greater attention should have been paid to this from the outset: 'The companies involved should be made aware of the diversity of occupational cultures, in order to understand each other better; this is something that should be settled at the beginning of a project: team building' (GEL manager).

Clearly, the collaborative work we have been observing for two years shows that cooperation is not intrinsic but is learnt as part of a gradual process. Building on the pioneer applied work 
of Brady and Davies, (2004) on Learning Capabilities, the first step in analysing this learning process is to identify the different levels - individual, collective and organisational - at which it takes place. At the individual level, it is the people involved in the collaborative projects who first learn to cooperate. Some learn how to manage this cooperation better, like the subproject managers on project A: 'I adapted, tried in the follow-up meetings, how shall I put it, to take everyone's interests into account'. Others learn, still individually, to identify their collaborator's specific values. For this engineer employed in the public research institute and working on project $\mathrm{B}$, it is now clear that 'the product aspect is very important for the client'. At the second (collective) level, it is the teams that collectively learn to cooperate with each other. Thus the manager in overall charge of project A noted that while 'the sub-projects still have slightly different ways of operating, we've become more mature'. The project reviews are occasions that reveal the learning processes the teams have been through: 'Things have progressed, since we used the experience gained from our first review to make things less of a scramble this time in terms of the deadlines for producing the deliverables' (sub-project manager project A). At the heart of this collective learning process is an improved ability to work together; this is true even of project $B$, where the two organisations involved thought they already knew each other: 'For more than a year now we've been thinking we've adjusted to each other well' (head of division).

One specific characteristic of the process whereby individuals working on collaborative projects learn to cooperate with each other is certainly that it is not only individuals and teams but also the organisations involved that go through the learning process, which for them involves better identifying the potential of their neighbours and partners. Thus one researcher, a member of his company's $\mathrm{R} \& \mathrm{D}$ department involved in project $\mathrm{A}$, noted that 'over and above the purely technical aspect, there are many, perhaps even more, knock-on effects in terms of knowledge of the ecosystem and of the others involved'. This experience was echoed by a participant on project B: 'We now have better knowledge of how [the partner private company] approaches things in terms of advanced development and industrialisation, we 
understand its problems better, and this in turn helps us to work more effectively upstream, doing the research'. Thus the type of learning observed at these three levels seems to be not only cognitive in nature (leading to changes in the representations of all involved) but also social and behavioural (Prencipe and Tell, 2001). One lever that plays a decisive role in encouraging such learning seems to be work on an 'intermediate objective' (Vinck, 1999). In project $\mathrm{A}$, this role was played by the period of experimentation with actual clients, which was finally launched earlier than planned; in project B, the intermediate objective crystallised around the need to clarify the nature of the end product. Figure 4 shows an overview of the cooperation building process over time

Figure 4 : The cooperation building process over 2 years

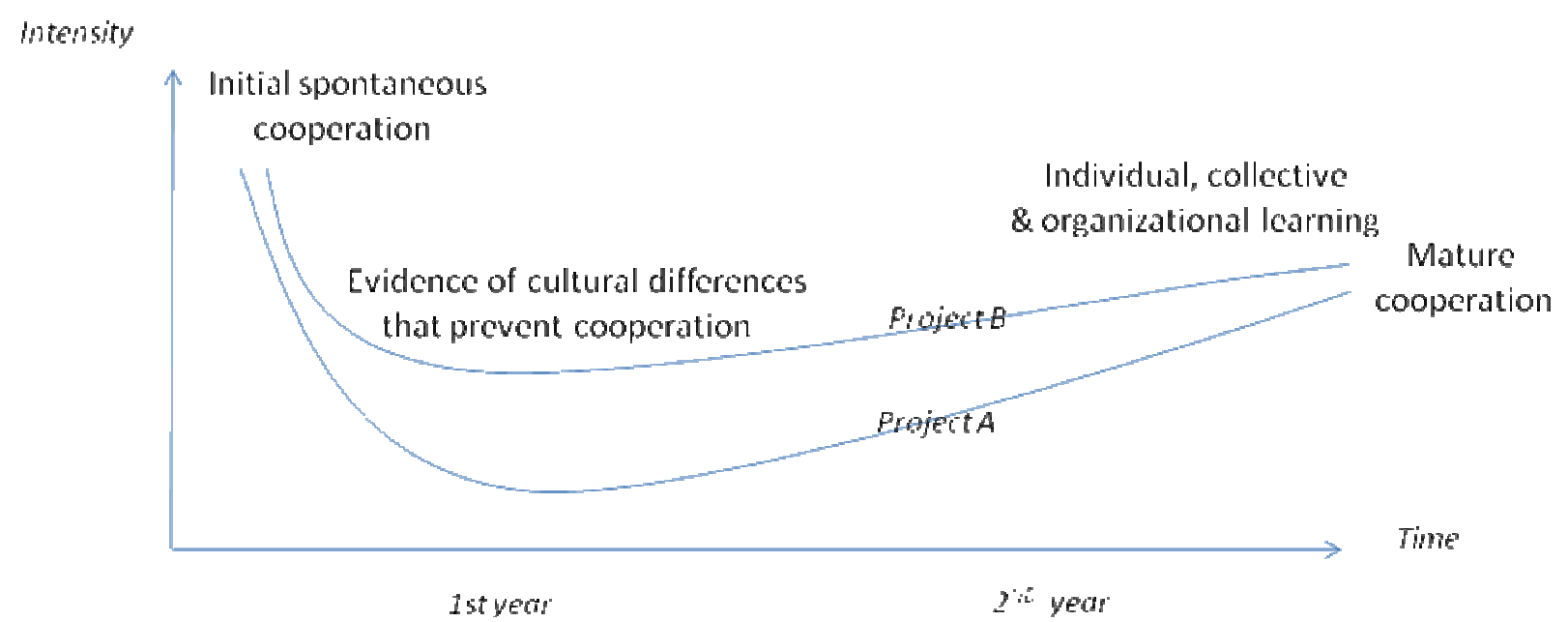

\section{Support from HRM: an additional lever to mobilise}

At the start of the two projects, it was clear to the actors that HRM issues were not part of their collaborative adventure, since each partner was continuing to manage its own employees. This initial situation has gradually changed. Indeed, an actual HRM support measure has been implemented, on project $\mathrm{A}$ as it happens. The project manager had voiced his concerns about the shared vision; his initial plan was to work with one of the HR 
managers from GEL in order to organise team-building days for the sub-projects already in progress. In the end, an operation was implemented not for these sub-projects but for a sixth one that was to be launched at the end of 2008. With support from the Minalogic cluster, a consultancy firm specialising in team building was selected and led a start-up training day for the team about to start work on this sub-project. Questioned just before the day's events took place, the manager in overall charge of the new sub-project was pinning considerable hope on this programme: 'The aim of this day will be to work and define the criteria for assessing the project's success, to get to know each other, to learn how to work together, to establish an atmosphere of trust, to learn how to deal with the arrival and departure of partners, to hammer out common objectives, and so on'. This manager, who had recently joined project A, surprised us with the maturity and sharpness of her thinking on the implementation of a collaborative project: 'In order to bring the team together, at the outset there will be a monthly planning meeting, it won't be a technical meeting. Everyone will be able to talk about the risks they are taking and their doubts (....), and there'll also be a human criterion, I'm very keen on that'.

Other avenues for HR support are currently being explored. The person with the strongest views on the subject, the $\mathrm{HR}$ director at the firm involved in project $\mathrm{B}$, first tried to persuade his counterpart at the public research institute to introduce a bonus that would be paid by both organisations, but for the moment at least his efforts have been in vain. However, the end of the projects is already being anticipated in terms of the HR issues that are likely to be raised and that will have to be dealt with sooner or later, particularly when it comes to recognising the gains made and the competences developed: 'What is important is that the collaborative projects are clearly recognised within the company. The head of a collaborative project should not be regarded simply as someone who brings in money and all the work that has to be done should be properly evaluated and recognised, since work that takes place outside of the firm ultimately remains more or less invisible, and management should be aware of this' (sub-project manager, project A). 
Consequently, following Bedin's (2008) recent contribution on People capabilities in PBO's, recommendations can be made with a view to encouraging, supporting and even dynamising this process, to the benefit of the collaborative work and of the innovation clusters that give their seal of approval to the projects. In terms of 'human resources', the levers that could be used to good avantage are located both upstream and downstream of the work that constitutes the heart of the project. Upstream, organising team-building and intercultural awareness events will encourage and accelerate the learning required for real cooperation to develop. Downstream, recognition of the individual competences acquired by project members is a guarantee of motivation and better career management for the organisations involved and for their employees, who are concerned to enhance the status of this work that takes place outside the firm' and which 'remains more or less invisible'.

On a more managerial level, it would seem that creating spaces or opportunities for team members to work physically alongside each other - which do not exist in all collaborative projects even if the partners are geographically close to each other - stimulate the learning required for collaboration: 'For communications to have been more effective, we should have been able to see each other a bit more, to work together physically', acknowledged a researcher on project B. The project's collective memory should be watched over and sustained, particularly in face of the risks posed by changes of personnel and managers over its course. And above all, even on an R\&D project, the concrete outputs or experimental creations should be increased in number, since it is they that catalyse the learning and development of competences.

Our findings and analysis highlight the strategic dimension that HR could play to foster collaborative projects performance (see Wright \& McMahon, 1992; Wright \& Snell, 1998 for a Strategic HRM perspective), echoing what some scholars have recently judged as crucial for the success of PBOs (Kamoche, 1996). "Human resource policies and practices must be seen 
not merely as administrative procedures for managing human resource flows, but as tools for building the HR capabilities required for PBOs to succeed."

Having been ignored during the start-up phase of these collaborative projects, the HR aspects were, as we have seen, brought back into play again by the actors in two ways. One was reactive, the other proactive.

Firstly, a 'reactive' or defensive set of useful measures would be intended to ensure that HRM does not pose any problems. This is the view that was prevailing when we were investigating project $\mathrm{B}$, where there was a desire to prevent differences in remuneration from creating tensions and putting a damper on collaboration. Thus it is possible to imagine that the partners might sign non-aggression pacts on recruitment (with each organisation undertaking, for the duration of the project, not to make any offers of employment to its partner's employees), that group bonuses might be harmonised (with all the members of the same team receiving the same amount at the same time, even though they may have different employees), or even that the opinion of the sub-project manager from whom an employee undergoing evaluation works part of the time might be officially taken into account.

Another series of useful HRM measures could be put together as the basis for a proactive strategy: such 'offensive' measures would seek to enhance the performance of collaborative projects by creating conditions favourable to the development of collaboration. In many innovation clusters, the launch phases of projects are limited to bringing participants together in a room in the presence of a representative of the financer and handing out the various parts of the project specifications. Why not organise team cohesion sequences on such occasions, which would enable each partner to identify the other's 'world' and to work with him on devising various methods of compromise? Moreover, collaborative work inevitably leads to some employees formulating alternative career plans (Huemann, 2007): every collaborative project could very conceivably be tracked by a mobility and careers officer who would conduct regular interviews with a view to noting any desires to move jobs and 
identifying the interest of any such mobility for individual employees and the employer. Finally, in tune with the sub-project managers we interviewed, who spoke of a lack of any 'directions for use' for those working on collaborative projects, the partners' human resources departments could make available a minimum set of tools for use by those leading these teams from different companies: methods of diagnosing sources of diversity, conflict resolution techniques, training in evaluation or refocusing interviews, etc. Analysis of the competences required, as well as a detailed evaluation of the competences actually available within the team, requires specific methods and tools: contributions and support in this area could prove to be very useful for project managers, not simply in order to identify and reduce differences but also to lend credibility to any requests for new resources they might make to the partner companies. By introducing such measures, HRM will undoubtedly be in a position to evolve from being a mere administrator within the partner companies to becoming a strategic partner (Ulrich, 1996) in joint innovation projects.

Finally, the (as yet unfinished) history of the two projects under investigation shows that the learning dynamic can be divided into two major phases. The objective in the first of these phases is to take the first steps towards collaboration, while the jointly conducted research remains very exploratory and open. After this very exploratory phase (lasting roughly 1 year), partners can then embody their joint efforts in an actual deliverable, such as as an experimental service or product, that is the manifestation of a collective (i.e. team) and interorganisational (i.e. produced by combining the partners' resources) competence. They have learned to developed coordination practices and overcome some of the cultural shock that comes from their differences; Projects can now move from a totally exploratory phase to another phase more focused on development: the co-production of a prototype or the production launch of a new experimental substrate was supported by modes of action, rules and guidelines that strengthened collaboration. This echoes one of the conclusions of Holmquist studies (Holmquist 2003) of learning in the context of development-oriented or 
exploratory-oriented innovations. The learning process of collaboration, supported by coordination tools and cooperative behaviours enables exploratory $\mathrm{R} \& \mathrm{D}$ projects to move to a more development-oriented phase. After 2 years, the continuous improvement process leads to a more mature collaboration within the project teams and between the partner organisations as well. Nevertheless, we have also seen that they do not prevent the partners from retaining their own specific objectives and hidden agendas or from failing to develop a fully common vision. Collaboration still remains an incomplete challenge.

Figure 5 : The collaboration building process over 2 years

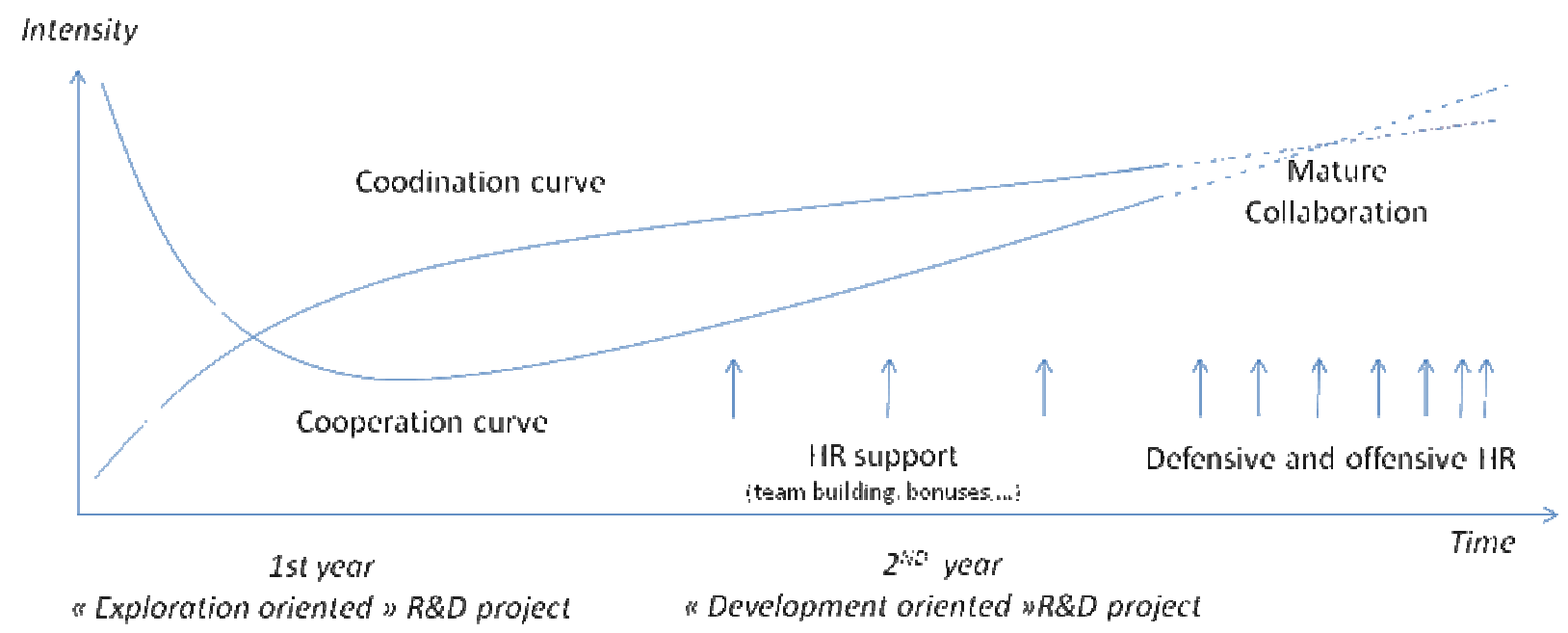

\section{Managerial implications}

At a time when organisational networks and collaborative innovation processes are proliferating in many economies, it would seem that one condition for their proper functioning is that the HR aspects of managing such processes be given their due weight. Over and above the coordination provided by the necessary reporting to financers and the standard methods of project management, greatest attention must be paid in the French innovation clusters to the dynamic of collaboration, which is otherwise highly likely to run 
out of steam over the years. It is here that HRM can further the performance of the clusters and their projects, both by anticipating the problems that might arise out of excessive differences in employment practices and by devising practices likely to facilitate that cooperation. Thus by virtue of its collaborative approach, technological innovation can encourage social innovation (Keegan \&Turner, 2002)

Continuous and longitudinal tracking of the various forms of collaborative work will provide the detachment required to enrich and channel our still limited knowledge of the management of inter-organisational projects. Does such management merely duplicate that of internal projects but within different boundaries? Or does it generate fundamentally different sets of problems? On initial analysis, it seems to us that certain aspects of standard project management are accentuated, such as the balance that has to be struck between contributions and rewards or the different cultures that have to be made to coexist. Thus several recommendations are necessary: clarify objectives at as early a stage as possible, increase the number of meetings and opportunities for informal exchanges and provide training in collaborative working.

In other ways, however, the management of collaborative projects opens up new opportunities. For organisations, collaborative working provides a learning experience. For employees, it provides new spaces for cooperation in a context in which social relations are impoverished (Philippon, 2007), as well as hitherto unsuspected opportunities for horizontal career moves. Thus co-innovation and the management thereof may be the vectors for renewal of management practices and processes. 


\section{Conclusion}

'Collaborative projects, they're people coming together to solve a problem. They're different from the relationship between a principal contractor and a number of subcontractors': behind the apparent simplicity of the concept, this statement by the manager of project A summarises in a few words the whole complexity of collaborative projects. The management of such projects has to respond to challenges that change during the various phases of the project.

As a growing area of interext for both researchers and professional, the question of how to build and manage collaboration in inter-organisational project opens up new and promising avenues for applied research.

This study, based on two different examples of collaborative projects within a global innovation cluster, bring a qualitative understanding on the complex dynamic process of collaboration. A two-step data collection ennabled us to identifie growing levels of both cooperation and coordination, eventhough the different actors involved don't fully share the same vision and the HR processes to support this dynamics are only at their early stage. A genuine collective learning process and competences development process has started. The issue for the future is to better support this human dynamic as a key factor for the projects successes.

This study, as an exploratory attempt to track a complex human dynamic over time, is limited in a number of respects. The specific features of the two case studies should necessarily limit the generalizability of our findings. On the methodological side, even if we sought to triangulate our findings, we relied most heavily on interviews and retrospective data collection. Our findings are inextricably tied to our qualitative approach. A different, more structured and quantitative research approach might lead to complementary insights. Although survey-based research seems difficult to develop in a confidential context, such additional investigations could be done in similar but less sensitive environments in order to overcome these limitations. 
More generally, this kind of research can contribute to a fruitful discussion about the conditions that have to be met for successful implementation of longitudinal and qualitative research protocols over extended periods of time. There are many difficulties that the researcher can expect to face and our experience enables us to highlight some difficulties and issue warnings. Firstly, the conditions and dates for the observations should be clearly negotiated in order to avoid exhausting or antagonising one's interviewees. Secondly, a balance needs to be struck between persisting with the initial questions and concepts and acknowledging the changes they undergo in the light of the realities being analysed. Thirdly, sufficient trust should be maintained in order to generate regular feedback sessions, which are sources of validation and possible adjustments that may be required in the course of the research.

As we write these lines, the second series of interviews required by our protocol is coming to an end, with a third series planned for 2010, during the final phase of the projects. During the next few months, we will be able to embark on a new phase of feedback and dialogue with our interviewees. In a way, research on collaborative work and the cross-fertilisation between the academic and industrial worlds is itself a collaborative adventure.

\section{REFERENCES :}

Alpha et Geste (2008), Etudes monographiques sur les implications des pôles de compétitivité dans le champ de l'emploi, de la formation, et des compétences, étude réalisée pour le Centre d'Analyse Stratégique, Paris, octobre, 82 p.

Arzeni S., Rousseau L., Verdier H., Veltz P. (2008), «Les pôles de compétitivité : une démarche paradoxale ? », Le journal de l’Ecole de paris du Management, n70, mars-avril.

Barnes T.,Pashby I.,Gibbons A. (2006) Managing collaborative R\&D projects development of a practical management tool, International Journal of Project Management, 24, p. 395-404. 
Bertrand H., Eskl R., Dayan J.-L. (2009), «Les pôles de compétitivité : des pôles de compétences ? », Centre d'analyse stratégique, novembre 2008, 6 p.

Boddy D., Macbeth D. (2000), "Prescriptions for Managing Change: a Survey of their Effects in Projects to Implement Collaborative Working between Organisations", International Journal of Project Management, vol. 18, ed. 5, pp. 296-306.

Brady T, Davies A. (2004) Building project capabilities: from exploratory to exploitative learning. Organ Studies, 25(9), 1601-21.

Bredin K (2008), People capability of project-based organisations: A conceptual framework International Journal of Project Management 26, 566-576

Browning L.D., Beyer J.M., Shetler J.C. (1995), «Building Cooperation in a Competitive Industry: Sematech and the Semiconductor Industry », Academy of Management Journal, 38, $1,113-151$

CM International et al. (2008), Recueil de bonnes pratiques de gouvernance pour les pôles de compétitivité, rapport réalisé pour la Direction Générale des Entreprises du Ministère de l'Economie, des Finances et de l'Emploi, janvier, www.competitivite.gouv.fr, 118 p.

Colle R. et al. (2009), "Quelle gestion des ressources humaines dans les pôles de compétitivité ? », Revue Française de Gestion, janvier 2009, pp. 143-161.

Darmon D. (2006), « Pôles de compétitivité : des accélérateurs de croissance », Annales des Mines, Réalités industrielles, février, pp.13-19.

Dameron S., Joffre O. (2007) The good and the bad : the impact of diversity management on co-operative relationships, International Journal of Human Resources Management, 18:11, p. $2037-2056$

DATAR (2004), «La France, puissance industrielle. Une nouvelle politique industrielle par les territoires. Réseaux d'entreprises, vallées technologiques, pôles de compétitivité », rapport de la DATAR, $131 \mathrm{p}$. 
Daude B. (2007), «Par la maîtrise des mécanismes de partenariat », Les ateliers de l'intelligence économique et de l'innovation, Besançon, mai.

DeFillippi RJ, Arthur MB. (1998) Paradox in project-based enterprise: the case of film making. California Management Review 40(2), 125-40.

Dherment-Ferere I., Bidan M. (2007), «Entre vocation extra-territoriale et ancrage local : quelle gouvernance pour les pôles de compétitivité? », Actes du colloque Prospective et Entreprise, 6 décembre 2007, Paris.

Drouin N, Bourgault M, Bartholomew S (2009) . Investigation of contextual factors in shaping HR approaches and determining the success of international joint venture project: Evidence from the Canadian telecom industry, International Journal of Project Management. Vol. 27, Iss. 4; p. 344

Duranton G., Martin P., Mayer T., Mayneris F. (2008), «Les pôles de compétitivité : que peut-on en attendre? », Cahiers du CEPREMAP, Editions ENS Rue d'Ulm.

Ebers M., Jarillo J.C., (1997), «The Construction, Forms, and Consequences of Industry Networks », International Studies of Management \& Organization, vol. 27, n4, p.3-21.

Fen-Chong S. (2006), «Trois réponses régionales à un processus national », Annales des Mines, Réalités industrielles, février 2006, pp.38-41.

Frery F. (1996), «L'entreprise transactionnelle », Annales des Mines, Gérer et comprendre, septembre 1996, pp.66-78.

Gerwin D., Ferris J. (2004) Organizing new product development projects in stategic alliances, Organization Science, vol 15, n 1, p. 22-37

Glaser B. Strauss S A. (1967). The discovery of grounded theory. Chicago: Aldine.

Heitz M. (2000), «Les coopérations interentrerprises: une grille de lecture», Finance Contrôle Stratégie, vol. 3, n, p. 57-81 
Hinkin T., Holtom B.C., Klag M. (2007), “Collaborative research : developing mutually beneficial relationships between researchers and organizations", Organizational Dynamics, vol. 36, ed 1.

Hobday M. (2000) The project-based organisation: an ideal form for managing complex products and systems, Research Policy 29(7/8), 871-94.

Holmquist M. (2003), “A dynamic model of intra- and interorganizational learning”, Organization Studies, 24-1, p. 95-123.

Huemann M, Turner R, Keegan A (2007) Human Resource Management in the projectoriented company: a review, International Journal of Project Management, 25, p.315-323

Mothe C., Quelin B. (2000), Creating competencies through collaboration: The case of Eureka R\&D Consortia, European Management Journal, vol. 18, n 6, p. 590-603

Kadefors A., Bjorlingson E., Karlsson A. (2007), "Procuring Service Innovations: Contractor Selection for Partnering Projects", International Journal of Project Management, May, vol. 26, ed 4, 375 .

Kamoche K (1996) Strategic Human Resources Management within a resource-capability of the firm, Journal of Management Studies, 33(2) 213-33

Keegan A, Turner RJ (2002) The management of innovation in project-based firms, Long Range planning, 35:367-88

KPMG (2007), « Pôles de compétitivité en France : prometteurs mais des défauts de jeunesse à corriger », KPMG Entreprises.

Le Boulaire M. et Leclair P. (2003), «Entreprise-réseau et gestion des ressources humaines : entre le modèle de la surclasse et celui des solidarités », Encyclopédie des ressources humaines, Paris, Vuibert, pp.1284-1296.

Mintzberg H. (1989), Mintzberg on management : inside our strage world of organizations, Free Press 
Philippon T. (2007), Le capitalisme d'héritiers. La crise française du travail, Paris, Seuil.

Picq T. et Retour D. (2001), «La coopération dans les organisations par projet », Personnel, n417, février, pp. 29-39.

Porter M. (1998), «Clusters and the New Economics of Competition”, Harvard Business Review, Boston, Nov/Dec.

Powell W. (1990), "Neither Market Nor Hierarchy: Networs Forms of Organization", Research in Organizational Behavior, B. Staw and L. L. Cummings, Jai Press. 12, pp. 295336.

Prencipe,A Tell F(2001). Inter-project learning: Processes and outcomes of knowledge codification in project-based firms. Research Policy, 30(9), 1373-1394.

Ratcheva V. (2009), Integrating diverse knowledge through boundary spanning processes. The case of muldidisciplinary project teams, International Journal of Project Management, 27, p. $206-215$

Retour D., Picq T., Defelix C., (2009) Gestion des compétences : nouvelles relations, nouvelles dimensions, Vuibert, $221 \mathrm{p}$.

Ruuska, I.,Teigland, R. (2009). Ensuring project success through collective competence and creative conflict in public-private partnerships: a case study of Bygga Villa, a Swedish triple helix e-government initiative. International Journal of Project Management, 27, 323-334.

Schaer J.-P. (2006), « Marketing politique ou nouvel élan pour l'industrie française ? Point de vue sur le premier forum des pôles de compétitivité », Réalités industrielles, février,

Shore B., Cross B.J. (2005), "Exploring the Role of National Culture in the Management of Large-Scale International Science Projects", International Journal of Project Management, vol. 23 , ed. 1 , pp. 55-64. 
Söderlund J. (2005) Developping project competence: empirical regularities in competitive project operations, International Journal of Innovation Management Vol. 9, No. 4, pp. 451480

Strauss (A.L.) \& Corbin (J.), Basics of qualitative research : Grounded theory procedures and technics, Sage, 1990.

Ulrich D. (1996), Human resource champions. The next agenda for adding value and delivering results, Havard Business School Press, 281 p.

Vinck D. (1999), «Les objets intermédiaires dans les réseaux de coopération scientifique », Revue Française de Sociologie XL, 2, p. 385-414.

Winter M, Smith C., Cooke-Davies T., Cicmil S. (2007), “The Importance of 'Process' in Rethinking Project Management. The Story of a UK Government-funded Research Network", presentation at University of Vaasa, $26^{\text {th }}$ April.

Wright P. \& Mahan G. 1992. Theoretical perspectives for strategic human resource management, Journal of Management, 18 (2): 295-32

Wright P.M \& Snell S.A. (1998) Toward a unifying framework for exploring fit and flexibility in strategic human resource management, Academy of Management Review, 23 (4): 756-77 